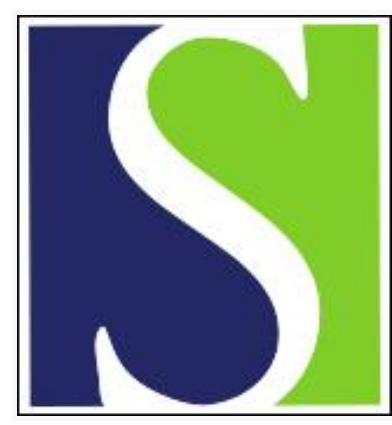

Scand J Work Environ Health 1995;21(4):301-309

https://doi.org/10.5271/sjweh.1365

Issue date: Aug 1995

\title{
Pleural mesothelioma in oil refinery workers.
}

by Wong 0

Refers to the following text of the Journal: 1994;20(3):213-215

The following article refers to this text: 1996;22(1):67

This article in PubMed: www.ncbi.nlm.nih.gov/pubmed/8553007

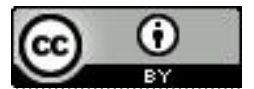




\section{Pleural mesothelioma in oil refinery workers}

In a recent publication, Gennaro et al (1) described mortality from pleural mesothelioma in a cohort of 1661 blue-collar workers at two oil refineries in northern Italy. Ten men were reported to have died from pleural mesothelioma, and the corresponding standardized mortality ratio (SMR) of 266, based on provincial rates, was statistically significant at the level of $\alpha=0.05$ [95\% confidence interval $(95 \%$ CI $) 128-489$ ]. I would like to raise some questions and offer some comments on the paper.

In the introduction of their paper, Gennaro et al cited a 1980 paper by Lilis et al, who suggested that the number of pleural mesotheliomas and lung cancers might be elevated among maintenance workers in oil refineries. As opposed to mesothelioma, lung cancer is a target of almost all cohort studies of oil refinery workers. Using meta-analyses, my co-workers and I have previously summarized mortality by cancer site for oil refinery workers (2). Based on all relevant studies available at the time, altogether 1903 lung cancer deaths were observed among oil refinery workers, compared with 2469.60 expected. The corresponding summary SMR for lung cancer was $77(\mathrm{P}<0.00001)$ and the $95 \% \mathrm{CI}$ was $74-81$. Furthermore, there was no difference in lung cancer mortality between operating and maintenance workers, or any upward trend by length of employment in refineries $(3,4)$. Thus, if lung cancer is used as a measure for asbestos-related cancers in refinery workers, there was no such increase. As for the study by Gennaro et al, results on lung cancer were not reported. Was there an increase in lung cancer in the two refineries in Genoa and La Spezia?

Considering available data on exposure to asbestos in refineries (primarily from the United States), one would not expect any significant increase in asbestos-related diseases. For example, in its evaluation of cancer risk associated with exposures in petroleum refining, the International Agency for Research on Cancer (IARC) (5) reported that asbestos exposures for employees working with pipe insulation ranged from 0.1 to 0.9 fibers per centimeter $\left(\mathrm{f} \cdot \mathrm{cc}^{-1}\right)$ and that the 8 -h time-weighted average concentrations during turn-around activities involving the removal of lagging, gaskets, and insulation ranged from 0.01 to $0.15 \mathrm{f} \cdot \mathrm{cc}^{-1}$. For insulation stripping and valve and joint repacking, measurements ranged from $<0.01$ to $0.02 \mathrm{f} \cdot \mathrm{cc}^{-1}$. Removing insulation from compressors generated $0.06 \mathrm{f} \cdot \mathrm{cc}^{-1}(6)$. Gennaro et al did not report any asbestos measurements for the two refineries in Genoa and La Spezia. It would be interesting to know whether asbestos exposures in these two Italian refineries were substantially higher than those recorded in refineries in the United States.

In numerous epidemiologic studies, shipyard workers (regardless of specific trades) have had a significantly elevated risk of mesothelioma (7). In particular, those who worked in shipyards during World War II were at even higher risk than other shipyard workers. The primary reason for the increased risk was the extremely high asbestos exposure in the enclosed environment on board vessels $(8-10)$. For example, fiber concentrations associated with the removal of blue sprayed asbestos ranged from 112 to $1906 \mathrm{f} \cdot \mathrm{cc}^{-1}$, and with bagging asbestos debris from 106 to $3815 \mathrm{f} \cdot \mathrm{cc}^{-1}(10)$. In northern Italy, several studies have reported increased risks for both lung cancer and mesothelioma among shipyard workers in Genoa (11), Trieste (12), and Monfalcone (13).

Gennaro et al stated that there was widespread asbestos exposure in both Genoa and La Spezia because of the shipbuilding industry in the two provinces, and they were correct in pointing out that employment at the shipyards could have been a major confounding factor in their study. Because of the rarity of mesothelioma and the extremely high risk associated with shipyard employment, even a few cases with previous shipyard exposure would have been sufficient to produce a spurious association. It would be important to obtain the complete (lifelong) employment histories of all 10 cases and to determine if any had been employed in the shipbuilding industry.

The median latency (time since first employment) among the 10 cases was 27.5 years. For pleural mesothelioma, the average latency was approximately 40 years for persons heavily exposed. For example, Giarelli et al reported an average latency of 47 years and a median of 48 years for persons with pleural mesothelioma in Trieste, most of whom were shipyard workers (12). For exposures at much lower levels (such as those encountered in refineries), the latency would have been much longer, even if it is assumed that such exposures could increase the risk of mesothelioma. The observation of a median latency of 27.5 years for refinery workers in the Gennaro et al study is, therefore, not consistent with the interpretation that the mesotheliomas were caused by refinery employment. More likely, exposures from previous employments contributed significantly, which would bring the median latency more in line with that of other studies. 
In the San Francisco Bay Area in northern California, many of the maintenance trades in the shipbuilding industry in the 1940 s or 1950 s moved to other industries such as oil refining as the demand for shipbuilding declined beginning in the 1960s. It appeared that the rise and fall of shipbuilding in northern Italy might be similar to that in northern California $(11,13)$. With a large population of workers with mixed exposures, it is important to assign appropriate weights to exposures from specific occupations, particularly in the presence of the extremely high mesothelioma risk associated with shipyard employment. McDonald \& McDonald (14) have developed a hierarchy for ordering the relative importance of asbestos exposure by occupation or industry. Apart from confounding exposures, the question of diagnostic comparability should also be examined. Gennaro et al stated that five cases had mesothelioma specified on the death certificates, while the diagnosis was less precise in the remaining five cases. It is not clear what "less precise" means and what rationale the authors used in arriving at the decision of assigning mesothelioma to the remaining five cases. The relevant question is "Would these five cases have been coded as pleural mesothelioma in the provincial or national mortality data?" According to both the 1991 abstract (15) and the 1994 report (1), it appeared that all cases were "documented" by a general practitioner. The fact that the findings of the entire study relied on one practitioner's judgment also raises some concern.

The issue is not the accuracy of diagnosis but rather the comparability of diagnosis. Doll \& Peto (16) have previously commented on the difficulties in interpreting comparisons based on noncompatible diagnostic criteria in studying asbestos-related neoplasms. Perhaps it would have been more balanced to present two SMR estimates, one assuming the remaining five cases were indeed mesothelioma and one assuming they were not. The two SMR estimates would have been 266 (95\% CI 128$489)$ and 133 (95\% CI 43-311), respectively. Thus the result of the study was completely dependent on the diagnostic decision of the five cases whose death certificates contained insufficient information. As a minimum, the actual causes of death listed on the death certificates should be reported in the paper so that the readers can make their own assessment.

With respect to the statistical analysis, there are also several questions. First, as stated in the introduction of the article, it appeared that the study was initiated by two clusters of mesothelioma previously discovered in the refineries. Strictly speaking, the P-value in hypothesis testing, such as that in a cohort mortality study, is only applicable to a priori hypotheses fully and explicitly formed before the data are examined (17). Otherwise the $\mathrm{P}$-value has a distinctly different meaning and carries a much reduced weight. The usual methods and formulas for testing hypotheses may be applied to post hoc hypotheses, but the usual interpretation may be profoundly weakened. If the population of a study is chosen in an a posteriori manner (such as choosing the two refineries with known clusters of mesothelioma cases), an ascertainment bias may be introduced which most likely increases the likelihood of demonstrating an excess (18).

Second, because of the limited availability of the reference rates of mesothelioma, the statistical adjustments in the study were inadequate. In cohort studies, the usual practice is to use five-year age intervals. Only three age groups $(25-54,55-74, \leq 75)$ were used by Gennaro et al. The rates within such wide age groups may not be homogeneous enough. For example, between 1980 and 1984 in the United States, the annual mesothelioma incidence rate for white males aged $70-74$ years was 115 per 100000 , which was substantially higher than the rate of 21 per 100000 for white males aged 55-59 years, a factor of more than fivefold (19). Yet these two age groups were combined into a single category in the Gennaro et al study. Furthermore, the reference rates were available for only three years (19751977), whereas the observation period of the study spanned approximately four decades. Instability of the reference rates presented yet another problem. How many deaths were the age-specific rates based on in each age group?

Third, the authors put much emphasis on the results for workers with more than 10 years of employment and 20 years of latency. How meaningful this result was depended on what other exposures the workers might have had outside the refineries. Certainly the amount of asbestos fibers inhaled even for a year or two at the shipyards during World War II would far exceed 10 years of exposure at oil refineries. For mesothelioma, a latency of 40 years rather than 20 years would have been more appropriate. Furthermore, the authors indicated that no consistent pattern was noted when the two refineries were analyzed separately.

Thus, although the analyses in this study might resemble those in a traditional cohort mortality study, the interpretation of the findings might have been substantially weakened as a result of the choice of refineries based on previously identified clusters, inadequate adjustments in SMR calculation, unstable reference rates, and incompatible diagnosis.

Although the authors made a cautious statement that the role of asbestos exposure inside the refineries could not be completely resolved on the basis of the reported data and that a case-referent study would be needed, the authors, nevertheless, concluded that pleural mesothelioma should be considered an occupational disease among oil refinery workers. On the basis of the questions and criticisms I have raised, such a conclusion appeared both premature and unjustified. 


\section{References}

1. Gennaro V, Ceppi M, Boffetta P, Fontana V, Perrotta A. Pleural mesothelioma and asbestos exposure among Italian refinery workers. Scand J Work Environ Health 1994;20: 213-5.

2. Wong $O$, Raabe GK. Critical review of cancer epidemiology in petroleum industry employees, with a quantitative metaanalysis by cancer site. Am J Ind Med 1989;15:283- 315.

3. Wong O, Morgan RW, Bailey WJ, Swencicki RE, Claxton K, Kheifets L. An epidemiological study of petroleum refinery workers. Br J Ind Med 1986;43:6_-17.

4. Dagg TG, Satin KP, Bailey WJ, Wong O, Harmon LL, Swencicki RE. An updated cause specific mortality study of petroleum refinery workers. Br J Ind Med 1992;49:203-12.

5. International Agency for Research on Cancer (IARC). Occupational exposures in petroleum refining; crude oil and major petroleum fuels. Lyon: IARC, 1989. IARC monographs on the evaluation of carcinogenic risks to humans, vol 45 .

6. Dynamac Corporation. Industrial hygiene assessment of petroleum refinery turnaround activities. Washington (DC): American Petroleum Institute, 1985.

7. Tagnon I, Blot WJ, Stroube RB, Day NE, Morris LE, Peace $\mathrm{BB}$, et al. Mesothelioma associated with shipbuilding industry in coastal Virginia. Cancer Res 1980;40:3875-9.

8. Selikoff IJ, Lee DHK. Asbestos and disease. New York (NY): Academic Press, 1978.

9. Cross AA. What to do about the asbestos currently in ships and industry? Ann NY Acad Sci 1979;330:379-81.

10. Harries PG. Asbestos hazards in naval dockyards. Ann Occup Hyg 1968;11:135-45.

11. Puntoni R, Vercelli M, Merlo F, Valerio F, Santi L. Mortality among shipyard workers in Genoa, Italy. Ann NY Acad Sc 1979;330:353-77.

12. Giarelli L, Bianchi C, Grandi G. Malignant mesothelioma of the pleura in Trieste, Italy. Am J Ind Med 1992;22:521-30.

13. Bianchi C, Brollo A, Ramani L, Zuch C. Asbestos-related mesothelioma in Monfalcone, Italy. Am J Ind Med 1993;24: $149-60$.

14. McDonald AD, McDonald JC. Malignant mesothelioma in North America. Cancer 1980;46:1650-6.

15. Gennaro V, Ceppi M, Fontana V, Beggi A, Puntoni R, Montemanni $\mathrm{M}$, et al. Is the oil refinery plant a dangerous workplace for pleural cancer? [abstract] Eur J Cancer 1991;27 suppl 3: 547.

16. Doll R, Peto J. Other asbestos-related neoplasms. In: Antman $\mathrm{K}$, Aisner J, editors. Asbestos-related malignancies. Orlando (FL): Grune \& Stratton, Inc, 1987

17. Bailar JC, Mosteller F. Medical uses of statistics. Waltham (MA): New England Journal of Medicine Books, 1986.

18. Schultz PA, Ehrenberg RL, Single M. Investigation of occupational cancer clusters: theory and practice. Am J Public Health 1987;77:52 - 6

19. Connelly RR, Spirtas R, Myers MH, Percy CL, Fraumeni JF. Demographic patterns for mesothelioma in the United States. JNCI 1987;78:1053-60.

Otto Wong, $S C D$

Applied Health Sciences

181 Second Avenue, Suite 628

PO Box 2078

San Mateo, California 94401, USA

\section{Author's reply}

We would like to thank Dr Wong for his precious comments on our paper (1), which enable a deep investigation of the relationship between asbestos in oil refineries and pleural mesothelioma and also the possibility to add some information based on a survey recently conducted in Genoa by the Unit of Hygiene and Safety in the Occupational Environment of the Local Health Authority (LHA) (2).

Pleural mesothelioma, which appears to be unrelated to cigarette smoking, is strongly associated with asbestos exposure and, as the use of such fibers has been documented in oil refining $(1-12)$, inhalation by refinery workers is likely. Therefore, we believe that the hypothesis of an increased risk of pleural mesothelioma for refinery workers is plausible.

\section{Pleural mesothelioma as a measure for asbestos-related cancers}

Our data are among the few which directly address the issue of the risk of mesothelioma among oil refinery workers. The analysis of lung cancer mortality proposed by Wong may add information, but it is questionable whether lung cancer can be used as a proxy for asbestos exposure, given the possible confounding of tobacco smoking.

Although Wong uses lung cancer as a measure for asbestos-related cancers among oil refinery workers in a meta-analysis (13) that shows a summary standardized mortality ratio (SMR) of 77 , some limitations of this exercise have been raised (14).

Oil refinery workers have been shown to smoke less than workers in other industries (15). Levin et al (16) reported a decrease in lung cancer risk of 70 due to smoking habits among male chemical workers. Thus it is not unlikely that part of the excess of lung cancer mortality observed in some oil refinery cohorts (6) might be also due to both polynuclear aromatic hydrocarbons (PAH) and asbestos exposure. In the study conducted by Gottlieb (17), a significantly elevated odds ratio (OR) for lung cancer [OR $2.4,95 \%$ confidence interval $(95 \% \mathrm{CI})$ $1.0-5.9]$ was observed for men who had been employed in skilled maintenance trades or operator jobs in petroleum refining and who had died at age 60 years or older 
(25 cases). In Italy Bertazzi et al (18) observed an elevated mortality risk for lung cancer (ICD-8162) versus a local reference (SMR 122, 95\% CI 82-175) and versus a national reference (SMR 199, 95\% CI 136-283). These workers had a low probability of being employed in the shipbuilding industry (and confounding by smoking could be excluded as sufficient explanation of the increase in lung cancer death. Rushton (19), in a mortality follow-up conducted among eight United Kingdom oil refinery cohorts, observed a deficit of risk from lung malignant neoplasms. Inversely, for laborers (254 cases) this cause of death was increased (SMR 115, 95\% CI 101-130). This study, such as others conducted by Hanis et al ( $20-22)$, have not been considered by Wong in his letter.

\section{Lung tumor in our Italian oil refinery cohorts}

When our two cohorts, located in Genoa and La Spezia, were combined (table 1), the preliminary summary SMR for lung tumor, based on 48 deaths among blue-collar workers, was 92 (95\% Cl 68-122) after comparison with the local reference, $117(95 \% \mathrm{Cl} 86-155)$ with the national reference, and 147 (95\% CI 108-194) with the internal reference.

For maintenance workers only, the SMR was 105 and 138 after comparison with local and national references, respectively, and 197 (95\% CI 113-320) with the use of the internal reference.

\section{Asbestos exposure in oil refineries}

In 1971 Smyth et al (10) reported a case of asbestosis in a 63 year-old man, diagnosed 45 years after exposure to asbestos started at age 16 years when he began to work in an oil refinery. He worked in various oil refineries during the next six years, where he was directly exposed to asbestos, working for one year on the installation of asbestos insulation.

Fiber levels near or at oil refining plants have been found to be between 2 and 3 fibers per milliliter $(3,4)$.
The 1990 survey of the oil refining and petrochemical industries in the United States, as reported by Mehlman $(4,5)$, found asbestos in boilers, building insulation, compressors, crude columns, drums, FCC-CAT crackers, furnaces, gaskets, wall boards, valves, piping, heat exchangers, roofs, storage tanks, towers, tile, turbines, transit $(\mathrm{A} / \mathrm{C})$, and other areas. The percentage of refinery workers exposed to asbestos from 1940 to 1990 during the installation, repair, and removal of asbestos was 81 , 90 , and $90 \%$, respectively, and more than half of the time (57\%) no precautions of any kind were taken by persons working with asbestos.

On the basis of 398 samples tested, the type of asbestos used in the oil refining and petrochemical industries were chrysotile (approximately 40\%), amosite (approximately $30 \%$ ), and a combination of chrysotile and amosite (approximately 30\%) (4). Information derived from the aforementioned survey showed that significant amounts of asbestos-containing products were used in the oil-refining industries in the United States in 19001990. Mehlman also reported that, in 1965, 721000 t of asbestos were used in these industries, prevalently in asbestos-cement pipe (137 $000 \mathrm{t}$ ), electrical insulation (22 $000 \mathrm{t})$, packing and gaskets $(22000 \mathrm{t}$ ). By 1988 the use of asbestos had decreased by 10 -fold to $71000 t$, and the most significant decrease during this time was in those areas where workers were the most exposed to asbestos fiber dust (23). Mehlman, showing many figures with various parts of a typical refinery with numerous instances of deteriorating insulation materials (asbestos) to which humans are exposed daily, observed that these findings are consistent with others $(7,8,24)$, indicating that a large percentage of petrochemical and oil refinery workers shows significant chest radiological changes due to exposure to asbestos.

\section{Asbestos exposure in one Italian oil refinery}

In our paper (1), we mentioned that in both cohorts fibers such as crocidolite, amosite, and chrysotile were detected, but environmental measurements were not reported. Only recently (February 1995) have we obtained

Table 1. Preliminary standardized mortality ratios (SMR) for selected causes in two oil refineries.

\begin{tabular}{|c|c|c|c|c|c|c|c|c|c|c|}
\hline \multirow[t]{3}{*}{ Causes ${ }^{a}$} & \multicolumn{5}{|c|}{ Unexposed workers } & \multicolumn{5}{|c|}{ Exposed workers } \\
\hline & \multicolumn{3}{|c|}{ Local referenceb } & \multicolumn{2}{|c|}{ National reference } & \multicolumn{3}{|c|}{ Local referenceb } & \multicolumn{2}{|c|}{ National reference } \\
\hline & Observed & Expected & SMR & Expected & SMR & Observed & Expected & SMR & Expected & SMR \\
\hline All deaths $(000-999)$ & 126 & 205 & $61^{*}$ & 204 & $62^{\star}$ & 449 & 576 & $78^{*}$ & 571 & $79^{*}$ \\
\hline All tumors $(140-239)$ & 34 & 60 & $57^{\star}$ & 52 & $65^{\star}$ & 144 & 167 & 86 & 145 & 99 \\
\hline Lung tumors (162) & 12 & 19 & 64 & 15 & 81 & 48 & 52 & 92 & 41 & 117 \\
\hline
\end{tabular}

a Code of the International Classification of Diseases (eighth revision) in parentheses.

- Provinces of Genoa and La Spezia.

${ }^{*} P<0.05$. 
(table 2), from the LHA, environmental measurements and information on the amount of asbestos and rock wool in the Genoa oil refinery during the period 19901994 (2). These measurements were carried out for workplace environmental hygiene control and in accordance with safety regulations during decoibentation and demolition, conducted by specialized companies (figure 1).

\section{Estimation of earlier amounts of asbestos in one oil refinery}

A total of $817 \mathrm{~m}^{3}$ of asbestos (amosite) and $2521 \mathrm{~m}^{3}$ of rock wool were found in selected areas of the Genoa refinery (table 2 ). In this refinery, there was large and exclusive use of asbestos until 1960-1961 (2). On the basis of the volume of rock wool detected in the refinery, the previous amount of asbestos was estimated. It was assumed that the original plant (built in 1948) used only asbestos because the use of man-made mineral fibers was not so widespread. Thus the rock wool detected in the plant replaced asbestos.

On the assumption of an average density of 250 $300 \mathrm{~kg} \cdot \mathrm{m}^{-3}$ for asbestos and an average density of 130 $150 \mathrm{~kg} \cdot \mathrm{m}^{-3}$ for rock wool and the replacement of asbestos with an equal volume of rock wool, $1821 \mathrm{~m}^{3}$ of rock wool corresponds to $455-546 \mathrm{t}$ of asbestos (2). After adding the weight of $817 \mathrm{~m}^{3}$ of asbestos, which was detected, we could estimate a total amount of 659-791 t of asbestos. This value is likely to be an underestimation since no data are available on the asbestos used in other areas of the plant.

\section{Measurement of environmental exposure to asbestos in the Genoa oil refinery}

The LHA observed that during 1990-1994 exposure to asbestos fibers was, almost always, maintained under the accepted limit of 0.1 fibers per milliliter $(25,26)$ in those activities in which all precautions to defend workers from asbestos have been taken. According to the LHA, it is likely that, in the past, exposure levels were greater than those observed during the period 1990-1994 for insulators, maintenance workers, and other blue-collar workers assigned to activities carried out in the same area.

\section{Pleural tumors among oil refinery workers}

Our findings are consistent with previous reports in the literature. von Bittersohl (24) and von Bittersohl \& Ose (27) reported 26 cases of mesothelioma from 1967 to 1971 among workers in the oil refining and petrochemical industries.

Table 2. Asbestos a and rock wool, in cubic meters and tons, in some areas of the Genoa plant, as estimated in 1990-1994 during decoibentation and demolition. ${ }^{\text {b }}$

\begin{tabular}{lcc}
\hline Oil refinery areas & $\begin{array}{c}\text { Asbestos } \\
\left(\mathrm{m}^{3}\right)\end{array}$ & $\begin{array}{c}\text { Rock wool } \\
\left(\mathrm{m}^{3}\right)\end{array}$ \\
\hline North area & 472 & 2361 \\
Thermal power station & 107 & 160 \\
South area & 238 & $\cdot \cdot$ \\
\hline Total & 817 & 2521 \\
& $(204-245 \text { tons })^{\mathrm{b}}$ & $(328-378 \text { tons })^{\mathrm{b}}$ \\
\hline
\end{tabular}

Total asbestos estimated ${ }^{\mathrm{b}} \quad 659-791$ tons (based on rock wool)

a This amount of asbestos (amosite in predominance) does not include the asbestos located in roofs, ovens, burners (in which crocidolite was detected)

- To estimate the weight, in tons, an average density of 250 $300 \mathrm{~kg} \cdot \mathrm{m}^{-3}$ was assumed for asbestos and an average density of $130-150 \mathrm{~kg} \cdot \mathrm{m}^{-3}$ for rock wool $\left(700 \mathrm{~m}^{3}\right.$ of rock wool find in topping 5 has been excluded because this specific tower was only recently built) (2)
Figure 1. An oil refinery area near a visbreaker furnace during removal of asbestos insulation around pipes in 1992 (source: UO -ISAL USL 3 Genovese).

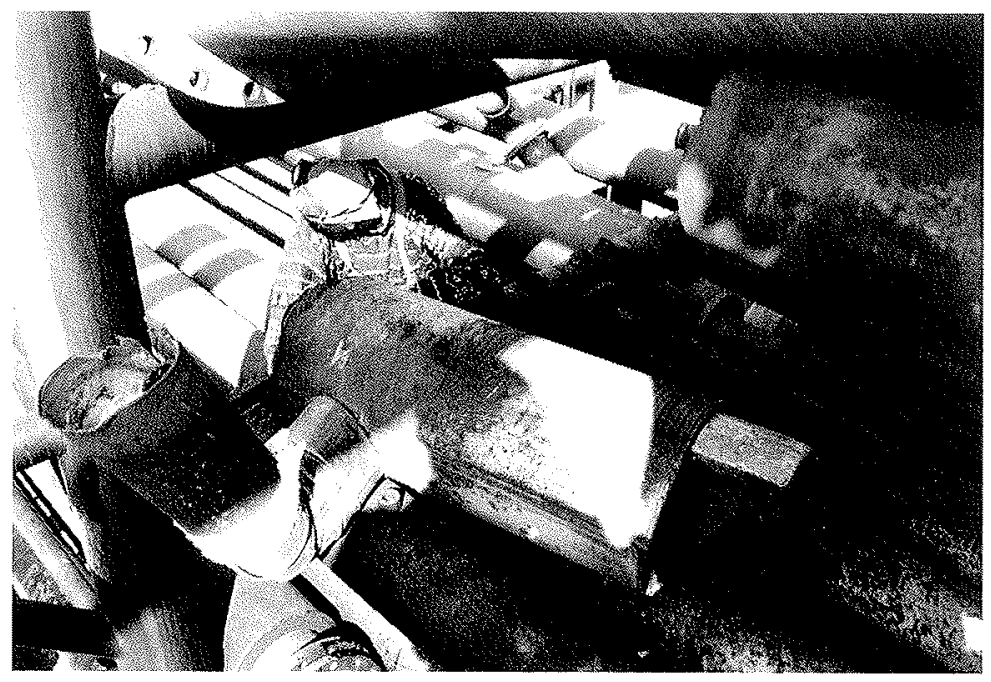

Scand J Work Environ Health 1995, vol 21, no 4 
Liveright et al (9) reviewed chest X-rays of 2100 workers employed in the oil refinery and petrochemical industry where asbestos was extensively used for insulation before 1972. Pleural abnormalities were more prevalent than parenchimal ones among workers with at least 20 years of employment. The authors concluded that there was a possibility of increased risk of lung cancer and mesothelioma for exposed workers, and they recommended that an SMR study be conducted. Recommendations were also made concerning workplace controls and practices, use of personal protective equipment, and the handling and storage of asbestos.

Del Nevo et al, in their presentation (11), reported five pleural tumor deaths among oil refinery workers in the La Spezia municipality when they examined 45650 death certificates in the period 1958-1988. Dodoli et al (12) reported a case of pleural tumor in the wife of an oil refinery worker exposed to asbestos fibers while repairing insulated pipes and boilers in an oil refnery. The woman used to wash the workclothes of her husband at home. Christie et al (28) observed an SMR of 390 (95\% CI 80-1100) for pleural tumor based on three cases in a prospective study of all employees of major petroleum companies operating in Australia and working in refineries, storage and distribution terminals, airports, and pro- duction facilities. Two of these cases had previous employment as fitters in industries with likely exposure to asbestos.

\section{Exposure to potential confounders}

Table 3 shows a positive relationship between the risk of pleural mesothelioma for the various categories of workers (with different probabilities of asbestos handling): low for white-collar workers, medium for blue-collar workers, and high for maintenance workers. The same relationship has been observed for lung tumors. In our study, as in other traditional cohort mortality studies, it was difficult to evaluate the role of asbestos exposure in jobs outside the industry under study. The use of a local reference population should provide a partial control for social characteristics and the local background of asbestos exposure. We linked the pleural tumor cases employed in the refinery with files of dockyard and shipyard workers analyzed previously in a cohort study (29), and no case was identified. In addition, we are tracing relatives of the mesothelioma cases. Currently, we have obtained the previous occupational history of seven cases (table 4). Only two workers had been previously employed in shipyards (as an electrician and as a carpenter).

Table 3. Standardized mortality ratios (SMR) for malignant pleural tumors among different groups of oil refinery workers. ${ }^{a}$

\begin{tabular}{|c|c|c|c|c|c|c|c|}
\hline \multirow[t]{3}{*}{ Group } & \multirow[t]{3}{*}{ Deaths } & \multicolumn{6}{|c|}{ Reference populations } \\
\hline & & \multicolumn{3}{|c|}{ Localb } & \multicolumn{3}{|c|}{ National } \\
\hline & & Expected & SMR & $\begin{array}{l}95 \% \text { confidence } \\
\text { interval }\end{array}$ & Expected & SMR & $\begin{array}{l}95 \% \text { confidence } \\
\text { interval }\end{array}$ \\
\hline White collar workers & - & 1 & 0 & & 0.2 & 0 & \\
\hline Blue collar workers & 10 & 3.1 & 328 & $157-602$ & 0.6 & 1714 & $822-3152$ \\
\hline Maintenance workersc & 5 & 0.9 & 547 & $178-1276$ & 0.2 & 2927 & $951-6831$ \\
\hline
\end{tabular}

a Age standardization conducted on the basis of seven age groups.

b Genoa and La Spezia provinces.

- La Spezia plant only.

Table 4. Blue-collar workers (males) with a pleural tumor.

\begin{tabular}{|c|c|c|c|c|c|c|c|c|}
\hline \multirow[t]{2}{*}{ Subject } & \multirow{2}{*}{$\begin{array}{c}\text { Born } \\
\text { (year) }\end{array}$} & \multirow{2}{*}{$\begin{array}{l}\text { Previous } \\
\text { shipyard } \\
\text { employment }\end{array}$} & \multicolumn{5}{|c|}{ Employment in oil refinery } & \multirow{2}{*}{$\begin{array}{l}\text { Death } \\
\text { (diagnosis } \\
\text { on death certificates) }\end{array}$} \\
\hline & & & Plant & $\begin{array}{c}\text { Year of } \\
\text { hire }\end{array}$ & Department & $\begin{array}{l}\text { Length } \\
\text { (years) }\end{array}$ & $\begin{array}{l}\text { Latency } \\
\text { (years) }\end{array}$ & \\
\hline 1 & 1933 & No & Genoa & 1952 & Maintenance & 1 & 12 & Pleural tumor \\
\hline 2 & 1901 & No & Genoa & 1952 & Thermal power & 12 & 28 & Pleural mesothelioma \\
\hline 3 & 1908 & Yes (electrician) & Genoa & 1960 & Electrician & 11 & 22 & Pleural heteroplasia \\
\hline 4 & 1922 & No & Genoa & 1962 & Compressor & 16 & 27 & Pleural malignant tumor \\
\hline 5 & 1936 & No & Genoa & 1960 & Maintenance & 29 & 31 & Pleural mesothelioma \\
\hline 6 & 1914 & Unknown & La Spezia & 1953 & Maintenance & 11 & 11 & Pleural tumor \\
\hline 7 & 1898 & Unknown & La Spezia & 1949 & Maintenance & 11 & 20 & Pleural mesothelioma \\
\hline 8 & 1900 & No & La Spezia & 1929 & Maintenance & 29 & 49 & Pleural mesothelioma \\
\hline 9 & 1901 & Yes (carpenter) & La Spezia & 1929 & Maintenance & 33 & 53 & Pleural heteroplasia \\
\hline 10 & 1928 & Unknown & La Spezia & 1959 & Maintenance & 25 & 29 & $\begin{array}{l}\text { Pleural tumor + other } \\
\text { causes }^{a}\end{array}$ \\
\hline
\end{tabular}

\footnotetext{
a Asbestosis and lung tumor.
} 
Therefore it is unlikely that asbestos exposure outside and before the employment in oil refineries could entirely explain the increased risk for pleural tumors observed among refinery workers.

\section{Latency}

In our study, the median time since first exposure for the mesothelioma cases was 27.5 years. For all cases the latency was greater than 10 (range $11-53$ ) years. The SMR values based on five cases with a latency between 20 and 30 years was 443 (95\% Cr 144-1033) versus the local reference and 2714 (95\% CI 881-6333) versus the national reference.

The SMR values based on three cases with a latency greater or equal to 30 years was 174 (95\% CI 36-509) versus the local reference and 1264 (95\% CI 261-3693) versus the national reference.

\section{Accuracy and comparability of diagnosis}

For five of the pleural mesothelioma deaths, the cause of death reported on the death certificate was pleural mesothelioma (4 cases) or the comparable pleural malignant tumor ( 1 case). For the other five pleural tumor deaths it was pleural tumor (3 cases) or pleural heteroplasia ( 2 cases). These definitions belong to 163.0 the category of the International Classification of Diseases, eighth revision, used in our provinces, where the diagnosis of pleural mesothelioma is often indirectly reported on the death certificates under different terminologies (11). Even though we did not include the two cases reported as pleural heteroplasia, the SMR remained significantly elevated versus both the local reference and the national reference populations.

In one cohort we also found (but did not include in this analysis) one peritoneal tumor (female), one pleuropulmonary tumor (male), and one mediastinum tumor (male). Finally, while in our paper, we stated that "all of cases were documented by a general practitioner" we did not mean that the physician was the same person in every case.

\section{Choice of refineries and mesothelioma clusters}

We have performed two independent cohort analyses in two refineries for occupational health purposes and preliminary results have been published $(30,31)$. Our original goal was to identify the risk of hematopoietic neoplasms. The preliminary results were nevertheless nonconclusive on this point, and our short communication was the first report of the final analysis of mortality among these workers. In the introduction of our short communication, we stated that "previous and prelimi- nary cohort studies of these populations revealed two clusters of mesotheliomas [p 213]." We recognize that the wording used in the paper was not optimal. In other terms, the two cohort studies among refinery workers were not chosen on the basis of the clusters. Mesotheliomas were discovered during the follow-up of the cohorts.

\section{Stability of the reference rates}

The period for mortality reference rates (1975-1977) was chosen because it was immediately available at the time of the analysis, and it was more reliable than that of the previous period. In any case, we recently reanalyzed mortality for mesothelioma according to 1969-1989 mortality reference rates. The SMR values did not change significantly in respect to either the local or the national reference populations since mesothelioma mortality is increasing in Italy (32) and most person-years in our cohort occurred before rather than after the period 1975-1977. This result would suggest that the local reference rates were overestimated and, consequently, the SMR was underestimated.

\section{Age groups}

The choice of few age groups may be justified by the small number of cases in the cohort. Bias in the SMR from lumping together various age groups would occur only if the person-year distribution within each stratum were different in the cohort with respect to the reference population. Since age at first exposure is below 55 years for all of the cases, no major differences can be expected in the 55- to 74-year age group (although workers may be, on the average, older than the reference population in the 25- to 54-year age group, which, however, contributed little to the total number of expected deaths). Combining two age intervals (more stability for pleural tumor rates based on only a few cases) is arbitrary but acceptable, and adequate adjustments in the SMR calculation were thus warranted. Nevertheless, when we used seven age groups (table 3), the SMR remained significantly high versus both the local reference (SMR 328, 95\% CI $157-602$ ) and the national reference (SMR 1714, 95\% CI $822-3152$ ) populations. Finally, table 5 shows the

Table 5. Deaths and age-specific mortality rates (per 100 000) of pleural mesothelioma among blue-collar workers in two Italian oil refineries.

\begin{tabular}{lccccc}
\hline & \multicolumn{5}{c}{ Age group (years) } \\
\cline { 2 - 6 } & $25-44$ & $45-54$ & $55-64$ & $65-74$ & $\geq 75$ \\
\cline { 2 - 6 } Deaths & 1 & 2 & 1 & 3 & 3 \\
Rates & 5.66 & 17.88 & 12.78 & 76.98 & 235.63 \\
\hline
\end{tabular}


number of deaths and the age-specific rates used in each age group.

The letter by Dr Wong suggests a possible overestimation of pleural tumor risk among oil refinery workers. Nevertheless, underestimation might be possible. In fact, it is possible that the pleural mesothelioma of some workers could have been erroneously diagnosed on the death certificate, as either lung tumor or other respiratory diseases.

We were cautious in our interpretation of the data; however, comparisons based on local rates may represent an underestimation of the true risk, given the high background mesothelioma mortality in the Genoa and La Spezia provinces, mainly due to the occupational exposure to asbestos in shipyards and in other work areas.

\section{Acknowledgments}

We are grateful to Dr Guiseppina Parello, Dr Giulio Andrea Tozzi and Dr Antonio Manti for their helpful comments. We also thank Mr Tom Willey for his technical assistance.

\section{References}

1. Gennaro V, Ceppi M, Boffetta P, Fontana V, Perrotta A. Pleural mesothelioma and asbestos exposure among Italian oil refinery workers. Scand J Work Environ Health 1994;20: $213-5$.

2. Tozzi GA, Parello G. I livelli di esposizione ad amianto in una raffineria di petrolio. Genova: Us1 3 Genovese - Servizio di Igiene u.o.ISAL ex Usl 10, 1995;1-8.

3. Nicholson WJ, Perkel G, Selikoff IJ. Occupational exposure to asbestos: population at risk and projected mortality: 1980 2030. Am J Ind Med 1982;3:259-311.

4. Mehlman MA. Dangerous and cancer causing properties ofproducts and chemicals in the oil refining and petrochemical industries: part IX, asbestos exposure and analysis of exposure. Ann NY Acad Sci 1991;368-88.

5. Mehlman MA. Dangerous and cancer causing properties ofproducts and chemicals in the oil refining and petrochemical industry: part V, asbestos-caused cancers and exposure of workers in the oil refining industry. Toxicol Ind Health 1991; 7(1/2):53-71.

6. International Agency for Research on Cancer (IARC). Occupational exposure in petroleum refining: crude oil and major petroleum fuels. Lyon: IARC, 1989. IARC monographs on the evaluation of carcinogenic risks to humans, vol 45 .

7. Lilis R, Daum S, Anderson H, Andrews G, Selikoff IJ. Asbestosis among maintenance workers in the chemical industry and oil refinery workers. In: Biological effects of mineral fibers. Lyon: International Agency for Research on Cancer (IARC), 1980:795-810. IARC scientific publication no 30 .

8. Zadeic G. A cohort study of occupational asbestos exposure related neoplasms in Texas Gulf coast area. Diss Abst Int B 1988:49(4):1118.

9. Liveright T, Gann P, McAna J. Exxon Corporation, Bayway Refinery and Chemical Plant, Linden, New Jersey. Cincinnati, OH: Hazard Evaluations and Technical Assistance Branch, NIOSH US Department of Health and Human Services, 1986.
Health hazard evaluation report no HETA 81 - 372-1727.

10. Smyth NPD, Goodman NG, Basu AP, Keshishian JM. Pulmonary asbestosis. Chest 1971;60(3):270-3.

11. Del Nevo M, Buselli R, Dodoli D, Taia T, Dini F, Paoli M, et al. Mortalità per mesotelioma pleurico nell'area di La Spezia (1958-1988). Atti del convegno nazionale: Mesoteliomi maligni ed esposizioni professionali ed extraprofessionali ad amianto 13-14 novembre 1990, Pisa, 48-50.

12. Dodoli D, Del Nevo M, Fiumalbi C, Iaia TE, Cristaudo A, Comba P, et al. Environmental household exposures to asbestos and occurrence of pleural mesothelioma. Am J Ind Med 1992;21:681-7.

13. Wong $O$, Raabe GK. Critical review of cancer epidemiology in petroleum industry employees, with a quantitative metaanalysis by cancer site. Am J Ind Med 1989;15:283 - 310 .

14. Kriebel D, Wegman DH, Moure-Eraso R, Punnett L. Limitations of meta-analysis: cancer in the petroleum industry. Am J Ind Med 1990;17:269—71.

15. Van Peenan PFD, Blanchard AG, Wolkonscky PM. Smoking habit of oil refinery workers. Am J Public Health 1984;874: $1408-9$.

16. Levin LI, Silverman DT, Hartge P, Fears TR, Hoover RN Smoking patterns by occupation and duration of employment. Am J Ind Med 1990;17:711-25.

17. Gottlieb MS. Lung cancer and the petroleum industry in Louisiana. J Occup Med 1980;22:384-8.

18. Bertazzi PA, Pesatori AC, Zocchetti C, Latocca R. Mortality study of cancer risk among oil refinery workers. Int Arch Occup Environ Health 1989;61:261 - 70.

19. Rushton L. Further follow up of mortality in United Kingdom oil refinery cohort. Br J Ind Med 1993;50:549-60.

20. Hanis NM, Stavraky KM, Fowler JL. Cancer mortality in oil refinery workers. J Occup Med 1979;21:167-74.

21. Hanis NM, Shallemberg LG, Donaleski DL, Sales EA. A retrospective mortality study of workers in three major US refineries and chemical plants, part I: comparisons with US population. J Occup Med 1985;27:283-92.

22. Hanis NM, Shallemberg LG, Donaleski DL, Sales EA. A retrospective mortality study of workers in three major US refineries and chemical plants, part II: internal comparisons by geographic site, occupation, and smoking history. J Occup Med 1985;27:361-9.

23. Bureau of mines minerals yearbook and Bureau of mines minerals facts and problems, 1989.

24. von Bittersohl $\mathrm{G}$. Epidemiologische untersuchungen uber Krebserkrankungen in der chemischen industrie. Arch Geschwulstforsch 1971;38:198-209.

25. Decreto Legislativo 15 agosto 1991, n 277 in Supplemento Ordinario al la Gazzetta Ufficiale n 200, 27 agosto 1991.

26. Legge n 257/1992. Norme relative alla cessazione dell'impiego dell'amianto. 27 marzo 1992.

27. von Bittersohl G, Ose H. Zur epidemiologie des pleuramesothelioma. Z Ges Hyg 1971;861-4.

28. Christie D, Robinson K, Gordon I, Bisby J. A prospective study in Australian petroleum industry, I: mortality. Br J Ind Med 1991;48:507-10

29. Puntoni R, Vercelli M, Merlo F, Valerio F, Santi L. Mortality anong shipyard workers in Genoa, Italy. Ann NY Acad Sci 1979;330:353-77.

30. Gennaro V, Fontana V, Beggi A, Ceppi M, Doria M, Garrone $\mathrm{E}$, et al. Regressione di Cox nell'analisi del follow-up di una raffineria di petrolio [Cox proportional hazard model in a cohort study among oil refinery workers in Genoa]. Folia Oncol 1991;14:295-302. 
31. Perrotta A. Mortalità per tumore in una coorte di lavoratori: il problema della standardizzazione dei tassi [dissertation]. Milan: University of Milan, 1993.

32. Merler E, Chellini E. Epidemiologia dei tumori primitivi della pleura [Epidemiology of primary tumours of the pleura]. Ann Ist Super Sanità 1992;1:133-46.

Valerio Gennaro, MD, ${ }^{1}$ Marcello Ceppi, MS, ${ }^{1}$

Vincenzo Fontana, MS, ${ }^{\dagger}$ Alessandra Perrotta, MS, ${ }^{2}$

Stefania Silvano, MD, ${ }^{3}$ Paolo Boffetta, MD
1 Environmental Epidemiology and Biostatistics, Istituto Nazionale per la Ricerca sul Cancro (IST), National Institute for Research on Cancer, Genoa, Largo Rosanna Benzi, 10 - 16132 Genova, Italy.

2 Chemical Carcinogenesis, Istituto Nazionale per la Ricerca sul Cancro (IST)

${ }^{3}$ Unit of Hygiene and Safety Occupational Environment of the Local Health Unit Liguria Region, Italy

${ }^{4}$ Analytical Epidemiology Unit, International Agency for Research on Cancer, Lyon, France. 